\title{
ESTIMATION OF SOME PHYTOCHEMICALS IN EXTRACT OF EGGPLANT PEELS AND CABBAGE LEAVES AND USING OF PIGMENT OF THEM IN DRINKS INDUSTRY
}

\author{
Bayan yaseen Al-Abdulla \\ Saad Dhamin Oleiwi
}

Food Sci. Dept. College of Agric. Tikrit Univ. Iraq

Email: saaddhamin2@gmail.com

\begin{abstract}
This study included the using of eggplant and cabbage residues in the extraction of natural pigments and study the determination of some phytochemicals and The alternatives to industrial pigments in the coloring of industrial drink. The pigments were extracted using distilled water and both (ethanol-methanol) acidified by $1 \%$ and $2 \%$ citric acid, the total phenolic content was estimated in these extracts. The result recorded highest content of phenolics $83.6 \mathrm{mg} / 100 \mathrm{~g}$ in methanol acidified extract for eggplant peels, while the highest content of distilled water extract was $147.5 \mathrm{mg} / 100 \mathrm{~g}$ for cabbage leaves. The content of anthocyanins, flavonoids, carotenes and tannins for eggplant and cabbage leaves, $(51.1,134.0)$ $\mathrm{mg} / 100 \mathrm{~g},(0.1,0.2) \mathrm{mg} / 100 \mathrm{~g},(15,25) \%,(0.008,0.099) \mathrm{mg} / 100 \mathrm{~g}$ was respectively. The concentration of apignen, kampherol, qurcetein and gallic acid recorded $(67.85,221.69),(73.70,172.00),(68.3,371.50),(62.5,238.10) p p m$ for eggplant and cabbage leaves respectively. The results of the sensory evaluation confirmed the success of the natural pigments derived from both sources in the production of concentrated industrial drink.
\end{abstract}

Key word: Eggplant, Cabbage , Dyes , phytochemicals , sherbet

Received:28/4/2019, Accepted:10/10/2019

\section{INTRODUCTION}

Eggplant fruits (Solanum melongena) have important medicinal properties because contain many phytochemicals which have been shown to be effective as anti-cancer, Can be gives the body an important source of antioxidants that work to curb the free radicals, Eggplant is used in many foods and is classified among the top ten vegetables in their antioxidant capacity (Nayanathara et al., 2016).

Antioxidant activities and phytochemicals such as phenolic substances are found in all eggplant fruit and in the first degree at its peels. Flavonoids are the most important of phenolic substances and the most prominent of these dyes are anthocyanins, which are the most common and important color materials in fruits and vegetables.

They are responsible for bright orange red colors to dark purple (Giusti and Wrolstad ,2003).

And what is said about what is recognized of the fruit of eggplant and its peels could be applied to cabbage leaves (Brassica oleracea), specially the colored cabbage and the red cabbage, which a great proportion of them is neglected when preparing for sale or manufacturing, it also contains flavonoids, which give their importance in the field of nutrition and food processing, The extraction of natural pigments from eggplant, red cabbage and all fruits and their manufacturing wastes 
and their use in the coloring of food products is a recent and promising trend to reduce the use of industrial dyes which are harmful to human health in terms of its responsibility for allergic reactions and possible carcinogenic effects, Natural dyes and colors have become very popular and preferable among consumers, in addition to the tendency of legislation and dietary laws to stay away from what is dangerous and doubtful for its safety (Rymbai et al.,2011).

Studies and researches were expanded about the use of natural colors to reach the types that meet goals required from adding colors to foods. These goals are coloring of non-colored foods, to give them attraction or to improve their color to better or compensation for food color affected by processing, Natural colors and pigments are usually used in baby food products, ice cream and sherbets (Machewad et al.,2012).

The objective of this research is to estimate some of phytochemicals content in eggplant peels and cabbage leaves extracts and coloring of sherbet by dyes present in the two studied fruit extracts.

\section{MATERIALS AND METHODS}

Materials and samples preparation: Locally grown varieties of eggplant and colored cabbage samples were collected from Tikrit market, sugar, citric acid and flavors (Turkey), ethanol and methanol (India).

Samples were prepared by cleaning the eggplant peel and cabbage leaves well. Eggplant were peeled with a sharp knife to get the peels without the core. The eggplant peels and cabbage leaves were cut into very small pieces and put in a ventilated oven at $50{ }^{\circ} \mathrm{C}$ until completely dried, then grinded well to be explorative for the extraction process.

Preparation of extracts: For ethanol and methanol solvents extraction, acidulated with citric acid, were used by $1 \%$ and $2 \%$ each, in addition to the use of distilled water on room temperature.

The dyes of dried and powdered peels of eggplant and leaves of cabbage were extracted according to (EL- Masry et al.2013):

1. $100 \mathrm{~g}$ of dry powder of eggplant peels or cabbage leaves were mixed with 200 $\mathrm{ml}$ of each of the solvents used above using the magnetic mixer in a $500 \mathrm{ml}$ flask for one hour and then left in the refrigerator overnight.

2. The mixtures were filtered using a mulch cloth and then Wattman No.2 filter paper was used to obtain the extract.

3. The extract was divided into two parts, one of them was kept in liquid form for estimation of total phenolic materials and the second which was extracted from distilled water extraction was dried at a temperature of $50{ }^{\circ} \mathrm{C}$ to be used later in sherbet making.

\section{Determination of total phenolic materials}

Total phenols were estimated in the studied samples using the Folin-Ciocalteu reagent method (Sadasivam and Manickam., 2008).

\section{Determination of total anthocyanins}


The total anthocyanin contents were determined spectrally according to the method described by Du and Francis (1973) at a wavelength of $535 \mathrm{~nm}$ and then using the following equation:

$$
\text { Total Anthocyanin mg/100g }=\frac{\text { Absorbance } \times \text { dilution factor }}{\text { Sample Weight } \times 55.9}
$$

\section{Determination of flavonoids}

Flavonoids were estimated according to the method used by Boham and Kocipai (1994) by extracting $10 \mathrm{~g}$ of the sample with methanol (80\%). The solution was then filtered with filtration paper and transferred to a known weight container and evaporatied on a water bath, Flavonoids percentage was calculated according to the remaining residue.

\section{Determination of carotenoids}

Carotenoids were estimated using Goodwin (1976) and the following equation was used for their calculation

$$
X=\frac{E Y}{e \times 100}
$$

Where: $\mathrm{X}=$ the amount of carotene $\mathrm{mg} / 100 \mathrm{ml}$ solution, $\mathrm{E}=$ reading the device at a wavelength of 480 nanometer, $\mathrm{Y}=$ size of final solution after acetone drying, $\mathrm{e}=$ Specific Extinction Coefficient of total carotenoids equals 2300.

\section{Determination of Tannins}

The tannins were estimated by El Kar et al (2013) by putting the sample in a test tube with $2 \mathrm{ml}$ of vanillin (1\% in $7 \mathrm{M}$ of $\mathrm{H} 2 \mathrm{SO} 4)$ in an ice bath and then incubated at $25{ }^{\circ} \mathrm{C}$ for a quarter of an hour and then reading absorption at a wavelength of 500 nanometer, Catechin was used to find the standard curve.

\section{Extraction of phenolic compound by HPLC}

The method mentioned by Seal (2016) and Mradu et al.(2012) was used to extract phenolic compound. One gram of each coarsely powdered peels or leaves was extracted using $5 \mathrm{ml}$ chloroform with constant stirring for 24 hours at the ambient temperature. The extract so prepared was filtered and the plant residue so left was macerated with the same volume of fresh solvent, stirred and filtered. The process was repeated twice and the extracts were combined. The extracts were finally filtered through $0.45 \mu \mathrm{m}$ PVDF membrane and the volume was made up to $10 \mathrm{ml}$ using the same solvent \& stored. The same processes were followed for the preparation of sample extract in methanol, $80 \%$ aq. ethanol and $1 \%$ aq. acetic acid solution.

Condition analysis :

- Mobile phase : ( A : B )

$\mathrm{A}=($ Methanol $:$ distilled water $:$ acetic acid $)(85: 13: 2)$

$\mathrm{B}=($ Methanol : distilled water $:$ acetic acid $)(25: 70: 5)$

- Column : C18 - ODS ( $25 \mathrm{~cm} \times 4.6 \mathrm{~mm}$ x $5 \mu \mathrm{m}$ )

- Detector : UV- $360 \mathrm{~nm}$

- Flow Rate : $0.8 \mathrm{ml} / \mathrm{min}$

\section{Making of Industrial concentrated Sherbets}

Concentrated sherbet was produce by according to method of Halaboo et al. (1995) by mixing the sugar in a vessel using hot pure water $\left(65 \mathrm{C}^{\circ}\right)$ to prepare a 
$65 \%$ sugar solution $5 \mathrm{~g}$ of citric acid per liter of syrup and $1.5 \mathrm{~g} / \mathrm{L}$ of the studied dye were added and mixed them with a part of the syrup and dissolved them well then filtered what may be precipitated syrup must be refrigerated, then $3 \mathrm{ml}$ of flavors was added, filled in the pre-sterilized bottles with their covers and kept in the fridge until evaluation.

\section{Sensory Evaluation of Concentrated Industrial sherbets}

The industrial sherbet produced from the extract of eggplant peels and cabbage leaves, was diluted with rate of $10 \%$, and compared with apple and pomegranate juice respectively, using the 9-degree Hedonic scale As follows: (1: Very unacceptable, 2: Extremely unacceptable, 3: Not moderately acceptable, 4: Not acceptable, 5: Average, 6: Fairly acceptable, 7: Moderately acceptable, 8: Highly acceptable, 9: Very acceptable) (Meilgaard et al. 1999).

\section{Total phenolic materials}

\section{RESULTS AND DISCUSSION}

Table (1) shows the content of total phenolic materials in eggplant peels and cabbage leaves, It is noted that the highest content in eggplant peels when using methanol $1 \%$ as extraction medium its value, was $83.6 \mathrm{mg} / 100 \mathrm{~g}$ while their values were $(49.7,43.6,12.7,10.5) \mathrm{mg} / 100 \mathrm{~g}$ for the extraction media of distilled water, methanol $2 \%$, ethanol $1 \%$ and ethanol $2 \%$, respectively.

These results confirm the findings of many researchers about the importance of studying methods of extraction of phenolic materials from fruits, Todaro et al. (2009) showed that phenolic content of the fresh eggplant peels extracted using acidulated ethanol was $88.73 \mathrm{mg} / 100 \mathrm{~g}$ while Nisha et al. (2009) reported that the use of methanol gave a value of $49 \mathrm{mg} / 100 \mathrm{~g}$, and when using ethanol $70 \%$ Eun-ju et al.(2011) got $55 \mathrm{mg} / 100 \mathrm{~g}$ in Eggplant peels.

The results of this study were within the values mentioned by the researchers above, in terms of the results of extraction with distilled water and methanol $1 \%$. The difference in the values of total phenolic materials is due to the types of solvents used in extraction their acidulated percent and their concentrations in the raw material and its growth rates. Eggplant and its variety and maturity are all factors affecting those proportions.

Table (1): Total phenolic content of Eggplant peel and Cabbage leaves extract

\begin{tabular}{|c|c|c|}
\hline \multicolumn{2}{|c|}{ Solvent type } & \multicolumn{2}{c|}{ The total amount of phenolic substances mg / 100 g } \\
\hline & Eggplant peel extract & Cabbage leaves extract \\
\hline $\begin{array}{c}\text { Distilled water } \\
\text { Ethanol with citric acid } \\
1 \%\end{array}$ & 49.7 & 147.5 \\
\hline $\begin{array}{c}\text { Ethanol with citric acid 2\% } \\
\text { Methanol with citric acid } \\
1 \%\end{array}$ & 12.7 & 137.5 \\
\hline $\begin{array}{c}\text { Methanol with citric acid } \\
2 \%\end{array}$ & 10.5 & 81.0 \\
\hline
\end{tabular}


Table (1) shows also the difference in the content of total phenolic materials extracted from cabbage leaves using the studied solvents. The highest percentage was reached $147.5 \mathrm{mg} / 100 \mathrm{~g}$ when distilled water was used as solvent, while the values were decreased to $(137.5,124.6,99.4,81.0) \mathrm{mg} / 100 \mathrm{~g}$ for extraction solvents (ethanol 1\%, methanol 1\%, methanol 2\%, ethanol 2\%), respectively.

It was noted increasing of phenolic materials compared to the study of Singh et al.(2006) and Leja et al.(2010) for the white and red cabbage respectively, as the range of values (12.58 - 34.41) and (31-43) $\mathrm{mg} / 100 \mathrm{~g}$ on the basis of fresh weight respectively, and they increased in the red than in white, while Wu et al.(2004) found that the American red cabbage content of total phenols was $254 \mathrm{mg} / 100 \mathrm{~g}$ on fresh weight, while Shihata et al. (2014) showed that phenolic content was 35.75 $\mathrm{mg} / 100 \mathrm{~g}$ using extraction with cold distilled water, and its value was increased using extraction with boiled distilled water for one hour to reach the value of 97.50 $\mathrm{mg} / 100 \mathrm{~g}$ on the basis of fresh weight.

\section{Content of some phytochemicals}

Table (2) shows the results of anthocyanins, carotenes, flavonoids and tannins in extracts studied. The content of anthocyanins in eggplant peels was $51.1 \mathrm{mg} / 100 \mathrm{~g}$ and this value was within the range obtained by Kumari et al.(2018), Which ranged between $(0-113.81) \mathrm{mg} / 100 \mathrm{~g}$ during estimation of these pigments in many of the genotypes studied which

had different colors: (white, green and purple), while the flesh of the fruits had low percentage of anthocyanins, They also observed a positive correlation of $(r=0,604)$ between their value in peels and flesh, Jung et al. (2011) attributed the difference in the percentage of pigments to the variety while the dark purple color was due to the concentration of anthocyanins and to the presence of pigment Delphidin which was modified by acylation process, In addition to what added as dark color by chlorophyll (Nothmann et al.,1976; Sadilova et al.,2006).

Table (2): The content of some plant chemicals in eggplant and cabbage crusts

\begin{tabular}{|c|c|c|}
\hline Component & Eggplant peel & Cabbage leaves \\
\hline Anthocyanins & $51.1^{*}$ & $134.0^{*}$ \\
\hline Flavonoids & $0.1^{* *}$ & $0.2^{* *}$ \\
\hline Carotenes & $15^{*}$ & $25^{*}$ \\
\hline Tannins & $0.008^{*}$ & $0.099^{*}$ \\
\hline
\end{tabular}

(*) $\mathrm{mg} / 100 \mathrm{~g}(* *) \%$

For anthocyanins in cabbage Pliszka et al. (2007) found large significant effect to the variety in their results, the highest value they reached was $100 \mathrm{mg} / 100 \mathrm{~g}$ for local cultivar (SWE), Value of anthocyanins in local cabbage understudy was $134.0 \mathrm{mg} /$ $100 \mathrm{~g}$, While Xavier et al.(2008) noted different in their contents red cabbage depending on extraction medium, they found that extraction and the use of acetic acid $20 \%$ volume / volume is the best among extraction. 
Flavonoids reached $0.1 \%$ in eggplant peels and they were high when compared to the results of Disotto et al.(2018), which amounted to $(0.014-0,039) \%$ of the fresh peels of the eggplant varieties they studied, Also, these values are high based on the classification of Peterson and Dwyer (1998), which classified the concentration of flavonoids in foods as follows: low (0.1 to 39.9) ppm, and medium (40.0 to 99.9) ppm, and high (higher than 100) ppm, This may be due to the fact that current study has used dried peels rather than fresh.

As for cabbage, Rokayya et al.(2011) noted that the value of flavonoids reached $7.72 \%$ in red cabbage and decreased to $3.91 \%$ in green cabbage, variety Capitata. These values are higher than those found in this study which reached $0.20 \%$, These high contents of flavonoids in some cabbage varieties are advised to be an important source of antioxidants.

Table (2) also shows the higher value of carotenes in cabbage than in eggplant peels $(25,15) \mathrm{mg} / 100 \mathrm{~g}$ respectively, while Tharasena and Lawan (2012) indicated that eggplant flesh is poor in these compounds as it contains $3,05 \mathrm{mg} / 100 \mathrm{~g}$ and their values varied between cabbage varieties to be the range $(5,46-57.19) \mathrm{mg} / 100 \mathrm{~g}$. Cabbage is rich in carotenes and therefore it is considered a source of vitamin A (Vuong,2000).

Table (2) revealed the value of tannins in both eggplant peel and cabbage leaves, which amounted to $(0,008-.099) \mathrm{mg} / 100 \mathrm{~g}$ respectively, It was noted that the scientific studies interested in the parts of the plant containing tannins, such as seeds and some cereals, especially in sorghum, and also Herbs, noting that some research estimated the value of tannins in eggplant flesh $4137 \mathrm{ppm}(0,4137 \%)$ (Alkurd et al.,2012), and this content increased in eggplant (Solanum aethopicum L.) to $3 \%$ (Eze and Kanu, 2014), while other scientific sources focused on conducting descriptive tests for the presence of tannins in plants and their parts.

\section{The concentration of some phenolic substances}

Figure (1) shows the concentration of some phenolic substances: apignen, kampherol, qurcetein and gallic acid, whose concentrations were $(67,85,73.70$, $68.3,62.5) \mathrm{ppm}$ for eggplant peel respectively, while their concentrations in cabbage leaves were $(221.69,172,00,371.50,238.10)$ ppm respectively.

The rates of these compounds vary according to the species, harvest time, maturity and environment. Breeding also produced new strains rich in one or more of these important compounds as oxidants, Disotta et al.(2018) observed that the highest concentration of apignen was $15.7 \mathrm{ppm}$ when they studied peels of modern strains of eggplant.

While Miean and Mohamed (2001) found that their concentration was $187 \mathrm{ppm}$ in Chinese cabbage while it was missing in most of the fruits of the tropical plants they studied. They were also missing in all of the African cabbage, African eggplant and eggplant of the Nakata variety (Yang et al.,2008), While the amount of qurcetein and kampherol was $(6.1,29.8) \mathrm{ppm}$ for the last two types of eggplant respectively, and decreased the concentration of gallic acid was in Polish eggplant to reach 1.49ppm (Kowalski and G. ,2005). 


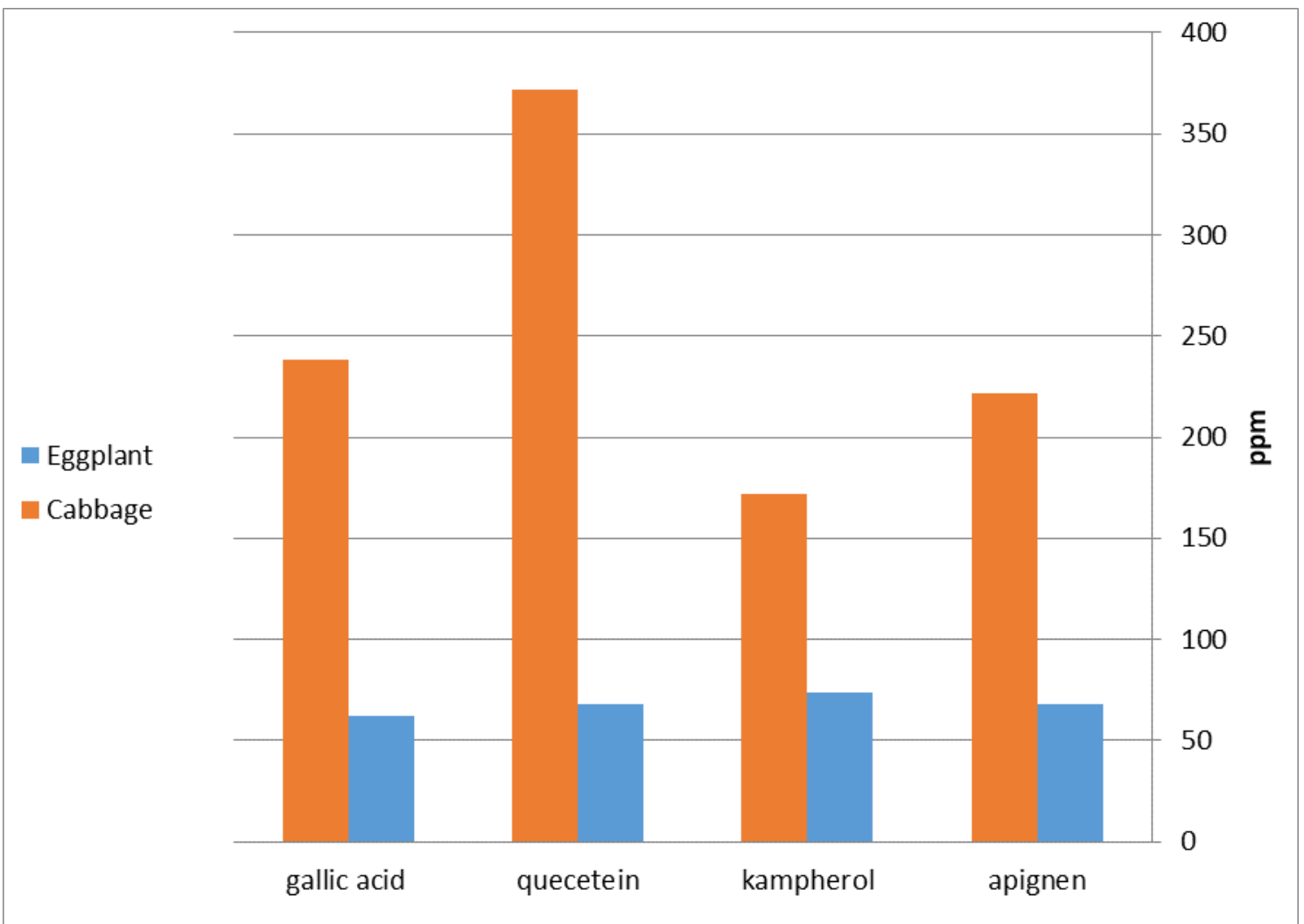

Figure (1): Concentration of apignen, kampherol, qurcetein and gallic acid In the peel eggplant and cabbage leaves

\section{Sensory evaluation of the product sherbet:}

This study included the production of the sherbet from the pigments extracted from eggplant peels and cabbage leaves and conducted sensory evaluation for products. Table (3).

The results showed that body values were equal of all sherbets where scored (8). This is due to evenness' the ratio of total soluble solids to the four sherbets respectively, as sucrose is the main component of these solids therefor it is reflected on their sensory evaluation.

The results also showed a decrease in the value of the flavor and taste of the drink produced using cabbage dyes, which reached $(7,6)$ respectively, and this may be due to the survival of some of the traces of sulfur compounds in cabbage, but the color decreased slightly in the sherbet produced from the extract of cabbage dyes and that may be due to the type and concentration of the pigments contained in these leaves and the method of extracting them in addition to the type of extraction medium. The results of the general acceptance scores $(8,8,8,7)$ for sherbets confirm the results of the evaluation of the sensory characteristics mentioned above. 
Table (3): Sensory evaluation of concentrated sherbet produced using eggplant and cabbage leaves

\begin{tabular}{|c|c|c|c|c|c|}
\hline $\begin{array}{c}\text { Concentrated } \\
\text { Juices }\end{array}$ & Texture & Flavor & Color & Taste & $\begin{array}{c}\text { General } \\
\text { Admission }\end{array}$ \\
\hline Sample control & 8 & 8 & 8 & 7 & 8 \\
\hline Eggplant Sample & 8 & 7 & 8 & 8 & 8 \\
\hline Sample control & 8 & 8 & 9 & 8 & 8 \\
\hline Sample Cabbage & 8 & 7 & 7 & 6 & 7 \\
\hline
\end{tabular}

$*$ Each value is average ten readings

In general, the results of the sensory evaluation confirm the success of the natural pigments studied in obtaining results close or similar to the artificial pigments used in the industrial sherbet, The results were consistent with those of Gamila et al.(2013) who also used the natural pigments (betalain) instead of the Carmine dye when producing ice cream.

The results also confirm the possibility of using plant wastes of eggplant crusts and neglected vegetable leaves as rich sources of plant chemicals, in addition to using them in the production of environmentally friendly dyes Eco-friendly.

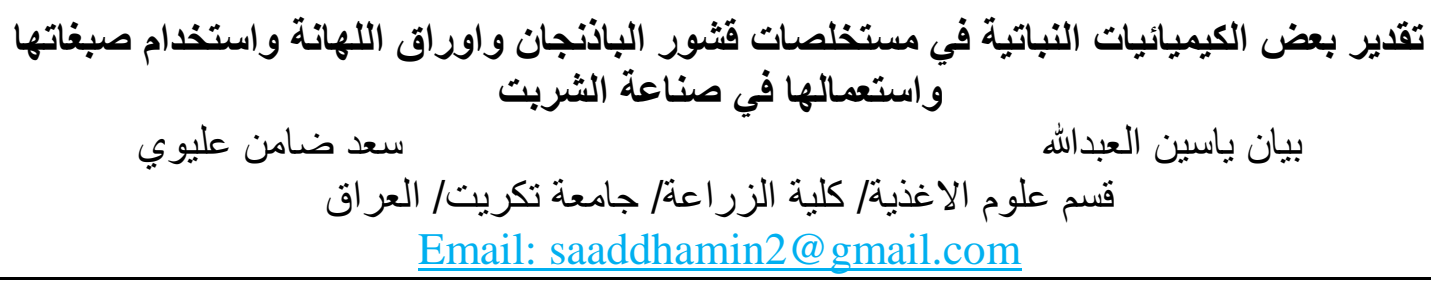

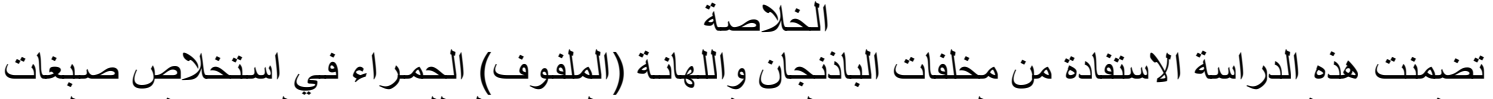

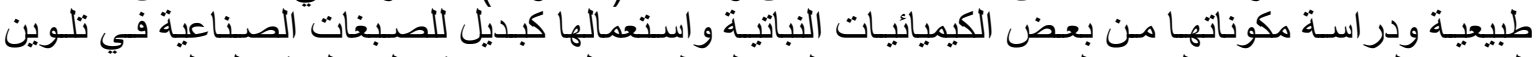

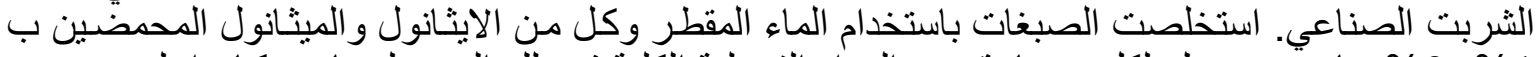

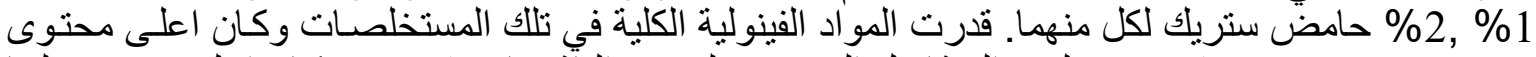

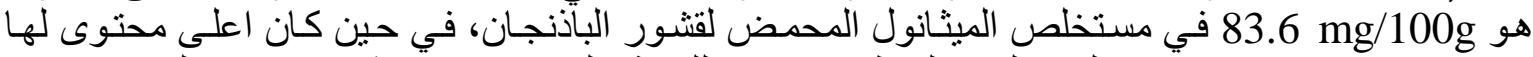
و 147.5 mg/100g

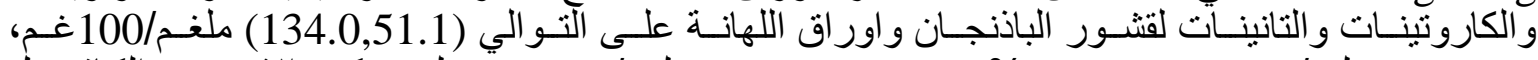

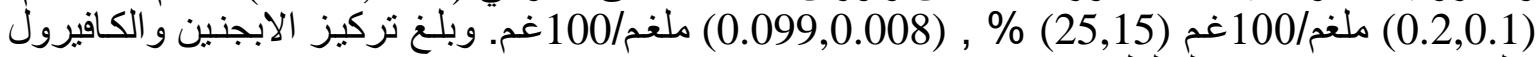

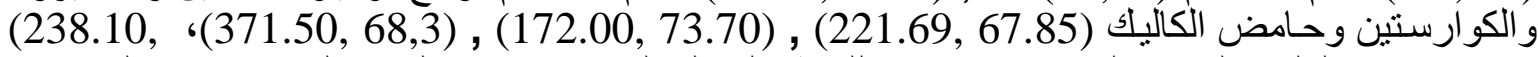

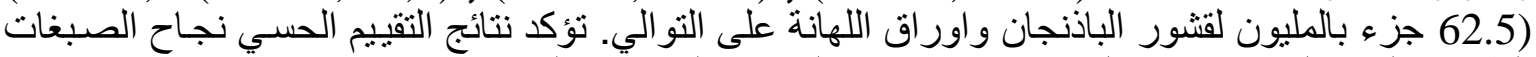

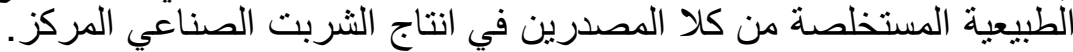

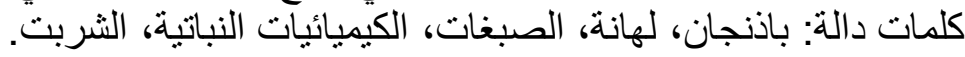
تاريخ الاستلام:2019/10/10، تاريخ قبول البحث:2019/4/28

\section{REFERENCES}

Alkurd, R.; Al-sayyed H.F. and Takruri H.R. .(2012). Tannins contents of selected plant used in Jordan. Jordon J. Agric. Sci.4(3).

Boham, A.B. and Kocipia, A.C.(1994). Flavonoids and condensed tannins from leaves of hawaian vaccininum vaticulum and vicalycinium. Pacific sci. .V(48): 458-463. 
Disotto, A.; Di-Giacomo, S.; Amator, D.; Locatelli, A. Vitalone, C.; Toniolo, G.; Rotino,R.; Scalzo,A.; Palamara,M.; Marcocci, and Nencioni,L. .(2018). A polyphenol rich extract from solanum melongena L. dr2 peel exhibits antioxidant properties and anti. herpes simplex virus type 1 activity In vitro. Molecules. 23:1-25.

Du, C.T. and Francis, F.J. .(1973). Anthocyanins of roselle (Hibiscus sablariffa, L.). J. Food Sci. .V(38):810-812.

EL - Massry Fatma H. M.; H. S. Hamed and F. A. EL - Ashwah.(2013). Red carrot roots processed wastes as a source of natural red pigments. Egypt. J. Agric. Res.V 91(3).

EL Kar, C.; Mtimet N.; Ferchichi A. and Bouajila J..(2013). Relationships between fruit acceptability and health- case of seven pomegranates (Punica granatum L.) Juices. Food and Nutrition Sciences.V(4): 119-130.

Eze, S.O. and Kanu C.Q. .(2014).Phytochem. And Nutr. Compos. Analysin of S. aethopicum L. JPSI3. V(4).

Gamila, A.Y.; Moussa, M.E.M. and Sheashea, E.R. .(2013). Characterization of red pigments extracted from red beet (Beta valgaris, L.) and its potential uses as antioxidant and natural food colorants. Egypt.J. Agric.Res.,91(3).

Giusti, M.M. and Wrolstad, R.E. .(2003). Acylated anthocyanins from edible source and their application in food systems. Bioch. Eng.J. 14(3),217-225.

Goodwin, T.W. (1976). Chemistry and Biochemistry of plant pigment, 2nd Ed. Academic press, London, UK.

Halaboo, S.A.S.; Bedee,A.Z.M. and Bekheet,M.A.A. .(1995). Food Technology, Cairo University, Agriculture college, Food Tech.Dept.(In Arabic).

Eun-ju,J.; Bae, M.; Jo, Y. and Lee, S..(2011). Antioxidant activity of different parts of eggplant. J. Medical plants Res.V5(18).pp 4610-4615.

Kowalski, R. and G. Kowalska..(2005).Phenolic acid contents in fruits of aubergine Solanum melongena. Polish J. Food Nutri. Sci., 14:37-41.

Kumari, A.; Chawla, W. and Dhatt, A.S. .(2018). Genotypic differences for anthocyanins in different parts of eggplant (Solanum melongena L.). Inter.J. of Adv. Res. in Bio. Sci. .V5(1):12-18.

Leja, M.; Kaminska, I. and Kolton, A..(2010).Phenolic compounds as the major antioxidants in red Cabbage. Folia Horticulture. Ann.22(1).

Machewad, G.M.; Ghatge P.; Chappalwar V.; Jadhav B. and Chappalwar A. .(2012). Studies on extraction of satflower pigments and its utilization in ice cream. J. Food process Technol.3:8.

Meilgaard, M.C.; Carr B.T. and Civille G.V..(1999).Sensory evaluation techniques. CRC press.

Miean, K. and Mohamed, S. .(2001). Flavonoids content of edible Tropical. $J$. Agric. Food chim. .49(6):pp 3106-3112.

Mradu,G.;Saumyakanti, S.; Sohini, M.; Arup M..(2012). HPLC Profiles of Standard phenolic compounds present in medicinal plant. Int. J. Pharm. And phytochemical Resh. 4(3):162-167. 
Nayanathera, A.R.; Mathews, A.; Aalolam,K.P. and Reshma,J.K. .(2016). Evaluation of total phenol, flavonoids and Anthocyanins content in different varieties of eggplant. Emer Life Sci. Res.2(2):63-65.

Nisha, P.; Abdul Nazar, P.; Jahamurthy, P. .(2009). A comparative study on antioxidant activities of different varieties of Solanum melongena. Food Chem. Toxicol. V(47):2640-2644.

Nothmann, J.; Rylski, I. and Spigelman, M. .(1976). Color and Variation in color intensity of fruit of eggplant cultivars. Sci. Horti. J. .V(4).191-197.

Peterson, J. and Dwyer J. .(1998). Taxonomic classification helps identify Flavoid containiny food on a semiquntitative food frequency questionnaire. $J$. Am diet. Assoc. V(98):677-685.

Pliszka, B.; Mieleszko, E.; Ciolkowska, G.H. and Wierzbicka,B.W. (2007). Content of anthocyanins and their antioxidative properties in various cultivars of red head Cabbage. J. Elementol.12 (3).

Rokayya, S.L.; Chan-Juan Li Ying and S. Chamg Has.(2011). Cabbage (Brassica oleracea L. Var. capitata) phytochemicals with antioxidants and antiinflammatory potentical. Asian pac. J. Cancer prov. 14(11);6657-6662.

Rymbai, H.; Sharma R.R. and Srivastav M. .(2011). Biocolorants and its implication in health and food industry. A Review. Inter. J. of pharma. Tech. Reserch. $3(4): 2228-2244$.

Sadasivam, S. and Manikam A. .(2008).Biochemical Methods. 3th Ed. New Age Internation Publishers.

Sadilova, E.; Stintzing, F.C. and Carle,R..(2006). Anthocyanins, color and antioxidant properties of eggplant (Solanum melongena L.) and Violet pepper (Capsicum annuuml L.) peel extracts. https://www.researchgate. net/pubication/6805743.

Seal, T.(2016).Quantitative HPLC analysis of phenolic acid, flavonoids and ascorbic acid in four different solvent extracts of two wild edible leaves, Sonchus arvensis and Oenanthe linearis of North-Eastern region in India. $J$. Applied Pharm. Sci. Vol,6(02)157-166.

Shehata, A.N.; Mahmoud, A.E. and Abdou, H.M. .(2014). Quantification of total phenolic and total flavonoid contents in extracts of some Egyptian green leaves and estimation of antioxidant activity Reseerch. J. pharm, Biol. and Chim. Sciences. 5(6):266.

Singh, J.; Upadhyay, A.K.; Bahadur, A.; Singh, B.; Singh, K.P. and Rai, M..(2006). Antioxidants phyto chemicals in Cabbage (Brassica oleracea L. var. capitata). Sci. Hort. 108(3):233-237.

Tharasena, B. and Lawan, S.(2012). Content of beta-carotene, xanthophyll, luten and zeaxanthin in vegetable as thai Side dish. International Conference Nutri.Food Sci.,39:244-248.

Todaro, A.; Cimino, F.; Rapisarda, P. and Spagna, G. .(2009). Recovary of anthocyanins from eggplant peel. Food Chem. 114(434-439).

Vuong, Le.T. .(2000). Underatitized B-carotene rich crops of Vietnam. Food and Nutrition Bulletin. 21(2). UN university. 
Wu, X.; Gu, L.; Prior,L. and Mckay. (2004). Characterization of anthocyanins and proanthocyaniding in some cultivars in Ribes, Aronia and sambucus and their antioxidant capacity. J. Agric. Fd. Chem.52(26)7846-7856.

Xavier, M.F.; Lopes, T.J.; Quadri, M.G.N. and Quadri, M.B. .(2008). Extraction of red Cabbage anthocyanins: optimization of the operation conditions of the colum process. Brazilian Archives Bio. and Tech. J. .51:(1).

Yang, R.; Lin S. and Kuo G. .(2008). Contents and distribution of flavonoids among 91 edible plant species. Asia pac. J. clin. Nutrition. V17(51):275-279. 